\title{
Readiness potential of cortical area 6 preceding self paced movement in Parkinson's disease
}

\author{
JOHN A SIMPSON, ADNAN J KHURAIBET
}

From the Glasgow University Department of Neurology, Institute of Neurological Sciences, Southern General Hospital, Glasgow UK

SUMMARY The vertex Readiness Potential (RP) (Bereitschaftspotential) preceding self paced voluntary movements is reduced in duration and amplitude in patients with Parkinsonism. It cannot be used as an index for delayed initiation of movement. The negative potential is commonly replaced by a positive slow wave. In hemi-Parkinsonism, the abnormal RP is more apparent on moving the affected limb. The abnormal RP is related to the severity but not to the duration of Parkinsonism. Short-term fluctuations of akinesia and rigidity, spontaneous or caused by levodopa are associated with changes of RP duration and amplitude. The abnormality does not correlate with reaction or movement times. It is suggested that the Readiness Potential is a diffuse response of area 6 cortex (especially Supplementary Motor Area) evoked by pallido-thalamo-cortical afferents under dopaminergic control. It is not obligatory for pre-programming of voluntary movement. The authors postulate a dendritic potential of basket cells associated with a pallidal activated gate control of postural set.

Studies on the pathophysiology of Parkinson's disease have concentrated on rigidity, tremor and bradykinesia. The other characteristic feature, delayed initiation of voluntary movement is very obvious on clinical examination but has proved impossible to quantify because of the difficulty in determining the time of the volition. Reaction times are not suitable for studying this function since multi-synapse afferent pathways are involved and the efferent limb of the responses is not necessarily the same as in voluntary movement. What is required is a marker of the premovement cerebral activity associated with the decision to move. Recognition of pre-movement cortical potentials related to self-timed limb movements suggested the possibility that prolongation of a component of the pre-movement potentials might accompany the slow initiation of self-paced movements.

\section{Cortical Readiness Potential}

In the last 20 years, chronological data storage and

Address for reprint requests: Prof J A Simpson, Department of Neurology, Southern General Hospital, Glasgow GS51 4TF, UK.

Received 8 February 1986 and in revised form 7 February 1987. Accepted 11 February 1987 averaging of scalp potentials of the electro encephalogram have made it possible to recognise event-related potentials preceding as well as following a recurrent event. Slow potential shifts temporalls associated with self-paced voluntary movement have been subdivided into discrete or overlapping com? ponents. Different authors described three to eight or more components. For the present purpose we concentrate on a slow surface negative potential shift preceding voluntary movements which is recognised by all authors as the Readiness Potential (Bereitschaftspotential) and which can be recorded from all normal human subjects. It starts at an average of $850 \mathrm{~ms}$ before the onset of the associated movement (of head or limbs). It is bilaterally distributed over the cortex and increases with intentional engagement. ${ }^{1}$ It is most negative at the vertex and in pre-central derivations, decreasing in amplitude as the recording electrode is moved away from the vertex (with linked mastoid reference) and becoming surface positive at the frontal leads. For our purpose we will not review the literature on the readiness potential but adopt the criteria and terminology of Deecke et al $^{1}$ unless otherwise indicated.

At about $87 \mathrm{~ms}$ (average) before the movement (or about $50 \mathrm{~ms}$ before the electromyogram, EMG) the negativity at the pre-central region contralateral to the limb movement rapidly becomes more negative 
(motor potential, MP). In about $40 \%$ of subjects the motor potential is preceded by a sudden positive deflection (pre-motion positivity) starting about $117 \mathrm{~ms}$ before the movement $(86 \mathrm{~ms}$ before the EMG). ${ }^{1}$ These average times are very similar to those in our control subjects reported below. The motor potential has a maximum over the contralateral precentral representation field of the moving limb. It is probably associated with activity of the motor cortex initiating the pyramidal tract volley commanding the movement. The pre-motion positivity is currently attributed to activity in the parietal cortex, mainly right, possibly associated with command for a ballistic movement. Assuming that any delay between the decision to move a limb and its execution is unlikely to occur after the command signal at the motor cortex we have concentrated on the earlier cortical events represented by the so-called Readiness Potential (RP).

\section{Case Material}

Fifty-five patients with idiopathic paralysis agitans (Parkinson's disease) were examined. There were 33 male and 22 female, with an age range of 31-75 years. The right hand was dominant in 33 patients. The time from the first recognised symptom of the disease was recorded and each patient graded at the time of investigation for severity of Parkinsonism by the Webster Scale (in which an increasing score represents increasing motor disability). As control subjects we selected an age-matched normal person for each Parkinsonian patient (mean age 56 years).

All subjects were naive for the type of measurements to be described. The patient and control group were selected for ability to fulfil certain criteria:

1 Ability to concentrate on the test programme for a minimum of 60 minutes and a maximum of 3 hours without requiring to be roused.

2 Ability to see an irregularly presented light signal permitting him to make a predetermined movement in his own time. He must not be blind or deaf.

3 Ability to comprehend the test procedure,

4 Ability to stand unsupported.

5 Absence of previous thalamotomy or other brain surgery.

6 Absence of other serious disease, systemic or neurological.

7 Absence of significant depression or dementia.

8 Absence of antidepressant, antipsychotic or sedative drugs.

All patient and control subjects were free to refuse to take part in the investigation which was fully described by one of us. The research was approved by the Ethics Committee of the Institute.

Handedness was determined according to a modified Edinburgh Inventory. ${ }^{2}$ Subjects were trained to relax and their ability to do so checked by electromyography.

(1) Self-paced movement The subject was semi-recumbent in a comfortable position, unable to see the recording equipment. The room was sound damped with regulated tem- perature. The subject was instructed to relax until he saw a flash of red light indicating that the equipment was ready. He could then decide not to respond or, in his own time but not immediately after the clearance signal, to rapidly flex his right index finger and maintain the position for about $2 \mathrm{sec}-$ onds while continuing to fix the gaze on the signal lamp. He was asked to avoid all other movements, facial, lingual, masticatory, swallowing, head, trunk or limbs until the test movement was completed and the finger again relaxed. Irregular intervals of about 15 seconds allowed the subject to blink and longer rest periods were interpolated if requested. The first few responses were excluded from analysis to exclude a habituation effect which is more frequent in psychiatric patients. ${ }^{3}$ Fifty satisfactory self-paced movements were recorded, excluding epochs containing recording artefacts or in which the observer noticed unwanted movement, triggering from involuntary EMG activity, or failure to fix the gaze.

The electromyograph (EMG) of the flexor digitorum communis muscle (pars indicis) of the right upper limb was detected by surface electrodes, amplified (time constant (tc) $0.03 \mathrm{~s} ;-3 \mathrm{~dB}$ at $1 \mathrm{kHz}$ ) and rectified. A second channel (tc $3.0 \mathrm{~s} ;-3 \mathrm{~dB}$ at $10 \mathrm{~Hz}$ ) was used to record eye movements by detecting the electro-oculogram (EOG) from silver-silver chloride electrodes at the lower lateral canthus of the right eye and the facial skin above the nasion. (This disposition monitors vertical as well as horizontal eye movements and blinks.)

For recording the movement-related potentials from the scalp silver-silver chloride electrolyte-filled cup electrodes were fixed with collodion to degreased skin which was lightly scratched with a blunt needle until the measured electrode impedance was not more than $5 \mathrm{kohm}$. Electrodes were placed at locations $\mathrm{Cz}, \mathrm{Fz}^{\prime}, \mathrm{Pz}^{\prime}$ and $20 \mathrm{~mm}$ in front of the somatosensory hand area on right (RHM) and left (LHM) in the montage described by Shibasaki, Barrett, Halliday and Halliday. ${ }^{4}$ The potential of each of the electrodes was referred to that of a linked-mastoid reference electrode and each recording pair connected to its own amplifier (tc 3.0 s; $-3 \mathrm{~dB}$ at $10 \mathrm{~Hz}$, input sensitivity $50 \mu \mathrm{V}$ for 1 volt output) through a terminal board which could be switched to a calibrator which was commanded by a computer controlling the warning light and recording programme.

Amplifier outputs were fed in parallel to pen recorders and through $A / D$ converters (8 bits resolution, $4 \mathrm{~ms}$ sampling interval) to a microcomputer for averaging. We used an opisthochronic averaging program (reverse computation) triggered from the electromyograph whenever the rectified EMG exceeded a predetermined threshold of approximately $40 \%$ of the maximum EMG voltage. This program allowed simultaneous averaging of all channels, covering a period from $1500 \mathrm{~ms}$ before to $500 \mathrm{~ms}$ after the movement onset. Fifty movements (free from artefacts or spurious triggering) were accepted for averaging to improve discrimination, though premovement potentials could be identified in an average of half this number, occasionally on a single trial. Data were stored on a computer disc and the averaged recordings displayed on an oscilloscope and an X-Y plotter. A cursor program was used to measure the time of onset and the amplitude of averaged cortical potentials, with reference to a base line obtained by averaging the first $250 \mathrm{~ms}$ of each tracing. Negativity of the stigmatic scalp electrode with 
respect to the reference electrode was written out as an upward deflection. The various pre-movement potentials were identified by the criteria of Shibasaki, Shima and Kuroiwa. $^{5}$

(2) Reaction time and movement time Control and Parkinsonism subjects were instructed to press the "stop" button of a simple electronic clock as soon as they perceived a light bulb illuminated when the "start" button was pressed by the experimenter. The subject had his finger on the button. The time elapsing (Reaction Time) was displayed on a three digit light emitting diode display with a resolution of 0.01 seconds $(9.99 \mathrm{~s}$ fsd). To measure Movement Time the same test was carried out but the subject's resting position was with the index finger $18 \mathrm{~cm}$ away from the "stop" button. Right and left sides were tested in all subjects.

\section{Results}

Readiness Potential In 53 of the 55 normal control subjects we identified a negative Readiness Potential (N1) starting $800-1500 \mathrm{~ms}$ (occasionally earlier) before the onset of the rectified action potential of the muscle (EMG) used to trigger retrograde averaging of the scalp recorded EEG. It was bilaterally symmetrical and in most subjects continued in the last $250 \mathrm{~ms}$ into a more rapidly increasing Motor Potential (N2), which was asymmetrical, being of greater amplitude at the precentral and parietal electrodes of the hemisphere contralateral to the movement. Premotion positivity (P1) was less consistent but a post-
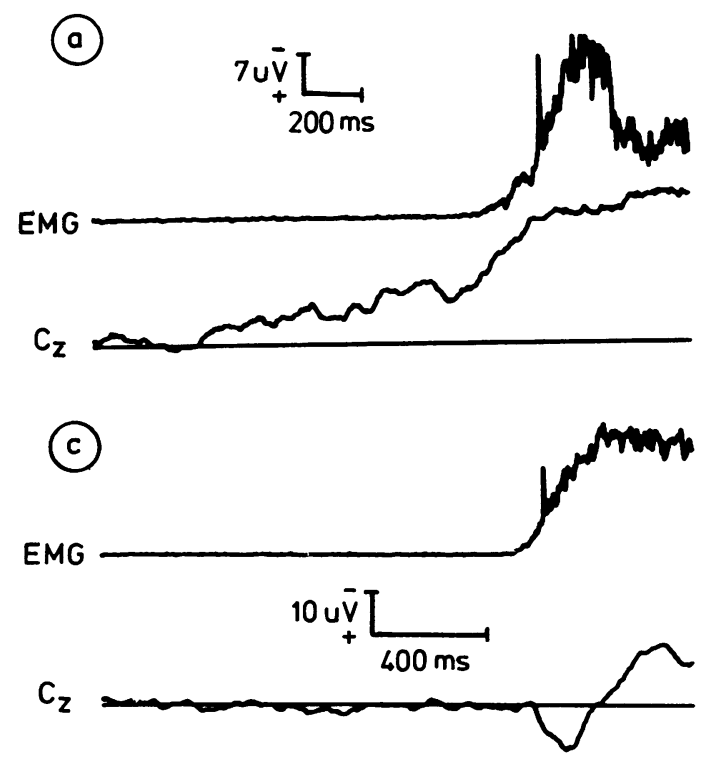

movement Reafferent Potential (P2) was usual. For the purposes of the present study, further discussion will be confined to the Readiness Potential (N1). The duration of RP exceeded $1100 \mathrm{~ms}$ in 43 subjects and it was $901-1100 \mathrm{~ms}$ in nine. Only three normal subjects had an RP less than $900 \mathrm{~ms}$ and none less than $800 \mathrm{~ms}$. The mean maximum amplitude (at onset of P1) was $10.4 \mu \mathrm{V}$ (SD 5.6) at the vertex but showed a tendency to decrease with age though the onset time did not. There was, for instance, no evidence that identification of the onset of RP was significantly affected by a drop in amplitude. In two normal adolescents (a boy aged 13 and a girl aged 14 years) the negative wave was replaced by a complex positivegoing wave starting about $500 \mathrm{~ms}$ before the EMG, but a negative wave began at about $300 \mathrm{~ms}$, presumably a Motor Potential (N2). This is normal in children and adolescents (see Discussion).

In 55 patients with Parkinsonism, there were only two with a negative Readiness Potential exceeding $800 \mathrm{~ms}$ in duration. In 23 patients there was a negative RP with duration less than 800 ms (mean duration $500 \mathrm{~ms}$ ), in three patients there was no detectable premovement potential and 27 patients had a positive slow potential shift which usually started $500 \mathrm{~ms}$ or less before the EMG (fig 1). Three patients in whomo the onset of RP could not be identified with reason able confidence were excluded from the statisticah analyses in the tables. In short, only $4 \%$ of these
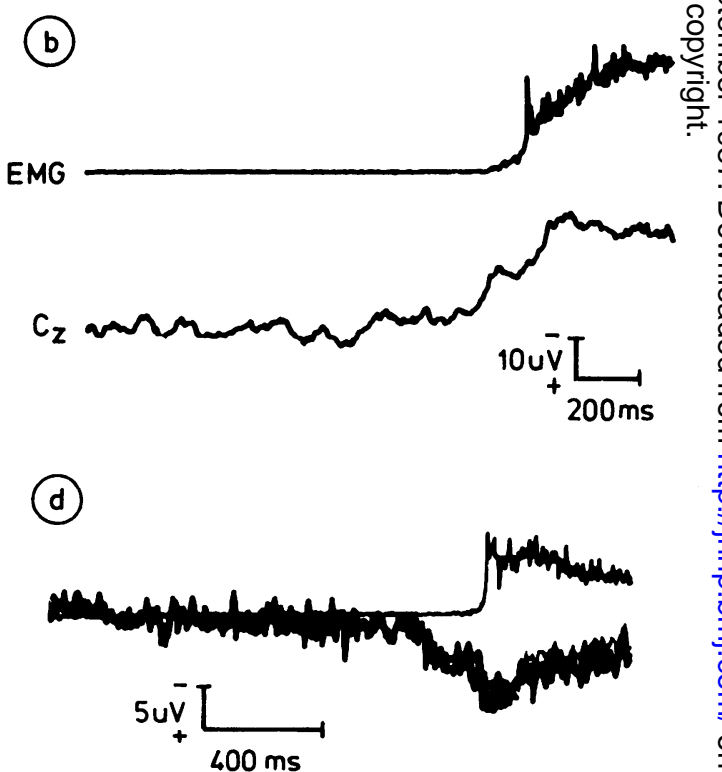

Fig 1 Types of pre-movement potentials recorded from $C z$ electrode in Parkinson's disease. (A) Negative RP with onset ( $952 \mathrm{~ms}$ before EMG) and amplitude within normal range. Note maintained negative deflection after onset of movement. (B) Negative RP of short duration ( $480 \mathrm{~ms}),(C)$ No negative RP. Onset of EMG is immediately followed by positive and negative deflections, (D) No negative RP. Positive wave starts about $500 \mathrm{~ms}$ before EMG. 
patients had a normal RP, $42 \%$ a reduced one and in $54 \%$ it was absent or replaced by a positive-going wave. In addition, where a negative RP could be identified at the vertex it was associated with a slightly later negative deflection at the contralateral hand motor area, but a still later positive deflection at the ipsilateral hand motor area and both parietal regions. Reaction and movement times Reaction and movement times were significantly prolonged in the patients with Parkinsonism but neither parameter was correlated with the duration or amplitude of the Readiness Potential (table 1). The Reaction Time of the Parkinsonism patients was $50 \%$ longer than the mean for controls, and the mean Movement Time was about $60 \%$ longer than the control mean, but when the patients were grouped according to the type of pre-movement potential (long, short, absent negative RP, or positive wave) there was no significant correlation.

\section{Correlation between the pre-movement potential and clinical features}

There was a little evidence that the abnormality of RP is related to the duration of clinical manifestations (table 2). The temporal correlation must be slight as shortened duration and diminished amplitude of the potential were clearly evident in patients with only 1-2 years of clinical symptoms, but there was a tendency for a negative wave, if present at all, to be shorter in duration in proportion to the length of illness. The reduction was significant at the $95 \%$ level after 2 years of illness. Where the clinical signs were more evident on one side, the RP was less negative or more positive and of later onset on the scalp contralateral to the more affected limbs. In unilateral Parkinsonism movement of the unaffected limb was preceded by more normal RPs (fig 2).

The patients were graded for severity of Parkinsonism by the Webster Scale (in which an increasing score represents increasing motor disability). There was a significant association of decreasing duration (late onset) and reduced amplitude of negative RP
Table 2 Effect of duration of Parkinsonism on RP

\begin{tabular}{llll}
\hline & & \multicolumn{2}{l}{ Readiness Potential } \\
\cline { 3 - 4 } Duration $(y r)$ & Cases & $\begin{array}{l}\text { duration }(m s) \\
\text { mean }(S D)\end{array}$ & $\begin{array}{l}\text { amplitude }(\mu V) \\
\text { mean }\end{array}$ \\
\hline$<1$ & 11 & $768(488)$ & -9.8 \\
$2-4$ & 9 & $510(293)$ & +0.9 \\
$5-10$ & 32 & $424(267)$ & -1.0 \\
Controls & 55 & $1228(187)$ & $-10 \cdot 2$ \\
\hline
\end{tabular}

with increasing Webster score, with absent RP or its positive counterpart being more common in cases with a high Webster score (table 3). This conclusion must be tentative as short or absent negative RP or positive waves were found at each grade on the Webster Scale but the findings in hemiParkinsonism support the proposition that the changes described are associated with the extent of the disorder.

We have considered the possibility that the abnormalities described could be pharmacological. We soon noted that if a patient was receiving levodopa in any form, there was generally no negative RP or it was replaced by a slightly positive wave whereas the latter was less common and negative RP a little longer with anticholinergic or amantadine treatment without levodopa (table 4). There were too few patients on bromocriptine or selegiline to assess the role of receptor stimulation by dopamine agonists. However, there were sufficient cases of abnormal RP in patients not receiving levodopa to make it improbable that the changes were the result of the drug. In this department it is usual to withhold dopaminergic therapy until there is considerable disability and so we propose that the apparent relationship with levodopa therapy is simply another indication that the cortical wave abnormality is associated with deteriorating Parkinsonism.

To test this hypothesis we examined the consistency of the responses and the effect of short-term fluctuations of the disease while on stable treatment regimes. Some patients did not show any significant

Table 1 Reaction and movement times compared with type of $R P$

\begin{tabular}{|c|c|c|c|c|c|}
\hline Subjects & No & $\begin{array}{l}r R T \\
\text { mean }(S D) m s\end{array}$ & $\begin{array}{l}I R T \\
\text { mean }(S D) m s\end{array}$ & $\begin{array}{l}r M T \\
\text { mean (SD) ms }\end{array}$ & $\begin{array}{l}I M T \\
\text { mean (SD) } m s\end{array}$ \\
\hline $\begin{array}{l}\text { Normal RP } \\
\text { Short neg RP } \\
\text { Absent RP } \\
\text { Positive RP } \\
\text { All Parkinsonism } \\
\text { Controls }\end{array}$ & $\begin{array}{r}2 \\
23 \\
3 \\
27 \\
55 \\
55\end{array}$ & $\begin{array}{l}335(35) \\
345(65) \\
356(142) \\
331(60) \\
347(66) \\
223(25)\end{array}$ & $\begin{array}{l}340(98) \\
344(73) \\
333(11) \\
324(57) \\
345(73) \\
237(39)\end{array}$ & $\begin{array}{l}660(113) \\
717(198) \\
786(244) \\
705(106) \\
717(199) \\
451(58)\end{array}$ & $\begin{array}{l}660(254) \\
739(183) \\
730(183) \\
695(117) \\
739(184) \\
462(58)\end{array}$ \\
\hline
\end{tabular}

$r=$ right hand response; $1=$ left.

RT = reaction time, the time interval between a visual stimulus and first motor response (finger on button).

MT = movement time, the time interval between a visual stimulus and same end point, but rest position of finger $18 \mathrm{~cm}$ from the button.

All responses of Parkinsonism patients are significantly $(p<0.001$ ) longer than controls but RT and MT are not significantly correlated with duration (or amplitude) of RP. 
(a)

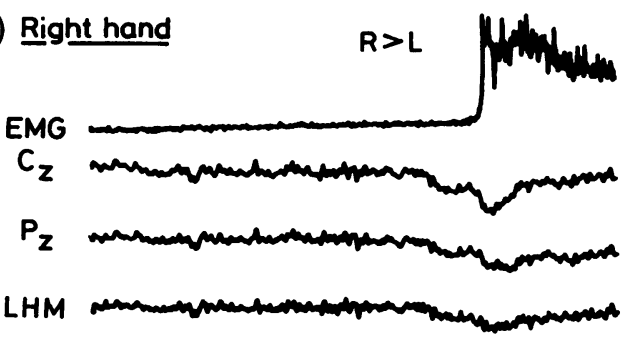

RHM

EOG

\section{(b) Left hand}

EMG
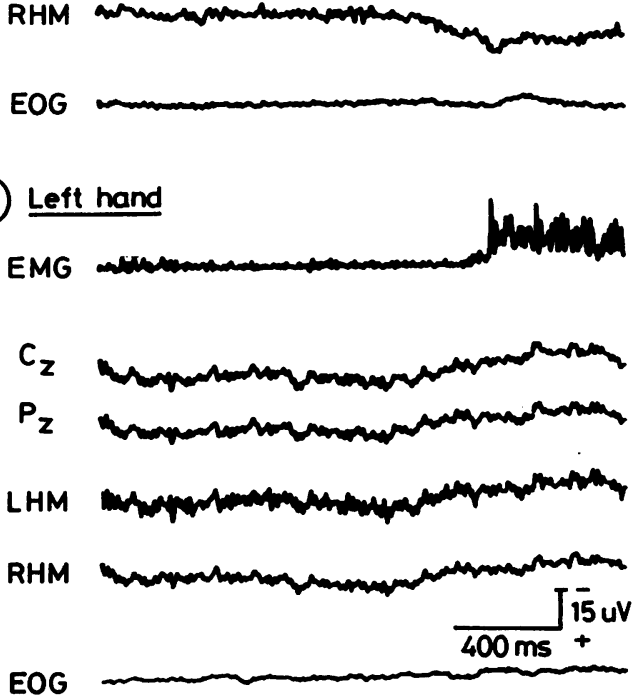

Fig 2 Right hemiParkinsonism in a right handed male $(50 \mathrm{yr})$. Self-paced flexion of index finger (EMG). Averaged recordings from $\mathrm{Cz}$ and Pz electrode positions. LHM and RHM over left and right hand movement areas respectively. Channel 6 monitors for eye movements (EOG). All scalp channels record a negative RP on movement of left index finger $(B)$ whereas all record a positive wave on movement of the right index finger $(A)$.

change on repeat examination 10 weeks later (fig 3 ). Others showed a marked shortening of RP duration or replacement with a positive wave on a "bad" day (greater bradykinesia) compared with a "good" day (fig 4). Even within a single day, levodopa treated patients with the "on-off" phenomenon showed associated variations of the pre-movement potentials. A positive pre-movement potential in an "off" period was replaced by a negative RP in the "on" period (fig 5). We conclude that the presence of a negative RP is associated with less akinesia, it is under dopaminergic control, but its absence does not indicate disconnection between the basal ganglia and the sources of the cortical potentials. It is not an obligatory concomitant of self-paced movement.
Table 3 Characteristics of RP related to Webster Clinical Scale score

\begin{tabular}{|c|c|c|c|}
\hline \multirow[b]{2}{*}{ Webster Score } & \multirow[b]{2}{*}{ Cases } & \multicolumn{2}{|c|}{ Readiness Potential } \\
\hline & & $\begin{array}{l}\text { duration (ms) } \\
\text { mean }(S D)\end{array}$ & $\begin{array}{l}\text { amplitude }(\mu V) \\
\text { mean }\end{array}$ \\
\hline $\begin{array}{l}0-5 \\
6-10 \\
>10 \\
\text { Normal controls }\end{array}$ & $\begin{array}{l}18 \\
18 \\
16 \\
55\end{array}$ & $\begin{array}{r}742(380) \\
380(228) \\
364(387) \\
1228(187)\end{array}$ & $\begin{array}{l}-5 \cdot 3 \\
-3.4 \\
+2.0 \\
-10.2\end{array}$ \\
\hline
\end{tabular}

\section{Discussion}

When these studies were made we measured the time of onset and the amplitude of averaged cortical potentials with reference to a base line obtained by averaging the first $250 \mathrm{~ms}$ of each recording. This base was used by Shibasaki, Barrett, Halliday and Halliday ${ }^{4}$ and previous workers. It is inadequate for some normal subjects with RP duration exceeding $1250 \mathrm{~ms}$ but we considered it to be suitable for the shorter duration RP recorded from all Parkinsonian patients. The fiducial point for retrograde measurement from the integrated EMG potential was more difficult to define because of the slower rate of rise of the integrated EMG in some Parkinsonian subjects. After our preliminary communication ${ }^{6}$ we were informed of a paper in press" on the "jitter" introduced by uncertainty of the EMG trigger point, but it appears that the variable trigger caused spurious lengthening of the RP duration and could not accoun for our findings. A recent investigation of the effect of introducing artificial delays ${ }^{8}$ showed that triggering delays of up to $500 \mathrm{~ms}$ could cause amplitude reduction of the RP but inspection of their fig 4 shows no significant shortening of the averaged pre-movement potential until the trigger delay exceeded $600 \mathrm{~ms}$. We calculated that mean jitter in our material would be of the order of $200 \mathrm{~ms}$, assuming Gaussian distribution. Our statistical analyses of differences take account of this degree of uncertainty. The uncertainty of timing

Table 4 Characteristics of $R P$ related to treatment in Parkinsonism

\begin{tabular}{|c|c|c|c|}
\hline \multirow[b]{2}{*}{ Therapy } & \multirow[b]{2}{*}{ Cases } & \multicolumn{2}{|c|}{ Readiness Potential } \\
\hline & & $\begin{array}{l}\text { duration (ms) } \\
\text { mean }(S D)\end{array}$ & $\begin{array}{l}\text { amplitude }(\mu V) \\
\text { mean }\end{array}$ \\
\hline $\begin{array}{l}\text { Levodopa } \\
\text { Nil } \\
\text { Other } \dagger \\
\text { Normal controls }\end{array}$ & $\begin{array}{r}41 \\
2 \\
9 \\
55\end{array}$ & $\begin{array}{l}424(263) \\
750\left(^{*}\right) \\
817(472) \\
1228(187)\end{array}$ & $\begin{array}{l}+0.5 \\
-10.7 \\
-12.5 \\
-10.2\end{array}$ \\
\hline
\end{tabular}

* Mean of two cases. One had a negative RP of normal duration, the other a very small negative RP.

$\dagger$ Anticholinergics, occasionally bromocriptine, amantadine or selegiline. 
(a) 12.6 .1984

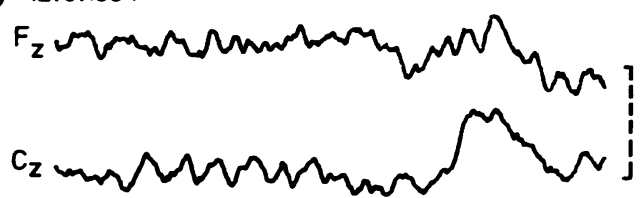

(b) 28.8 .1984

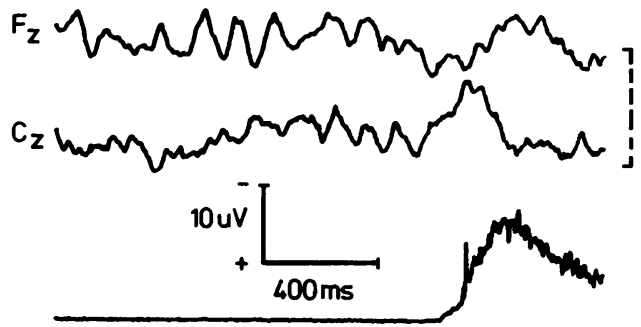

Fig 3 Averaged scalp EEG at Fz and Cz at intervals of 10 weeks in a patient with stable Parkinsonism. The negative RP recorded at $C z$ is unchanged.

the onset of RP does not differ between controls and patients since the RP gradient is the same in both populations. ${ }^{9}$ These authors have also reported that there was no difference between the RP of 10 patients with Parkinson's disease (nine on treatment) and that of normal old subjects. ${ }^{10}$ We have used healthy control subjects individually matched for age and sex and we do not agree with them if account is taken of duration as well as slope and amplitude of the premovement potential shifts.

Earlier reports were conflicting and not correlated with variations in the Parkinsonian syndrome. Deecke, et $\mathbf{l}^{11}$ investigated 33 patients with bilateral or unilateral Parkinsonism, selected for marked akinesia and minimal tremor. They found that the RP was bilaterally absent or even positive in 11 cases of bilateral Parkinsonism. In 22 unilateral cases it was significantly reduced in amplitude on the affected side of the brain. They did not record the duration of the RP. Groll-Knapp et al ${ }^{12}$ always recorded some slowly increasing negativity in cortical surface electrode recordings and noted that the peak occurred long after the time of the triggering movement. They comment that the start of the slowly rising negativity was rather late in these cases (no temporal data reported). Shibasaki et al, ${ }^{5}$ using scalp recording, noted reduced amplitude of RP bilaterally in 20 cases of idiopathic Parkinson's disease, but reported marked increase in the time interval from onset of the negative deflection to the EMG recorded from a muscle performing the test movement in 17 patients (in three cases the waveform was too disorganised to analyse). There was no correlation between the abnormality of RP and the severity of either tremor, rigidity or akinesia, which were assessed clinically but it was this report that suggested to us that the early onset of RP might be associated with difficulty in initiating movement though the Japanese authors found similar changes in subjects with cerebellar ataxia associated with cerebellar cortical degeneration. The RP was absent in disorders of the dentate nucleus and temporarily after $V_{\text {im }}$ thalamotomy in the patients with Parkinsonism. Papakostopoulos and Banerji ${ }^{13}$ reported that the RP amplitude was reduced in Parkinsonism to the same extent as in a normal control group of comparable age but it was sometimes suppressed. They did not report the duration of the RP. Studies contemporary
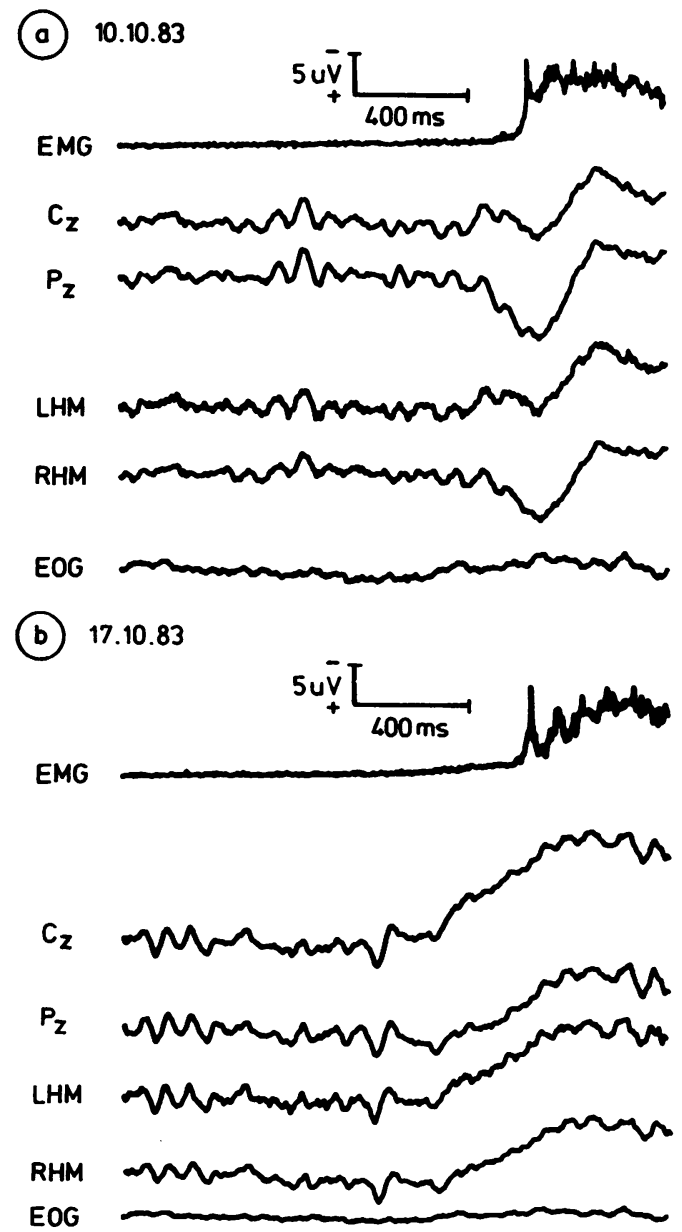

Fig 4 Parkinson's disease with clinical variability.

(A) recorded on a "bad" day has positive wave replacing $R P$.

(B) recorded one week later, on a "good" day shows a negative $R P$ of short duration. Symbols and recording channels as in fig 3. 


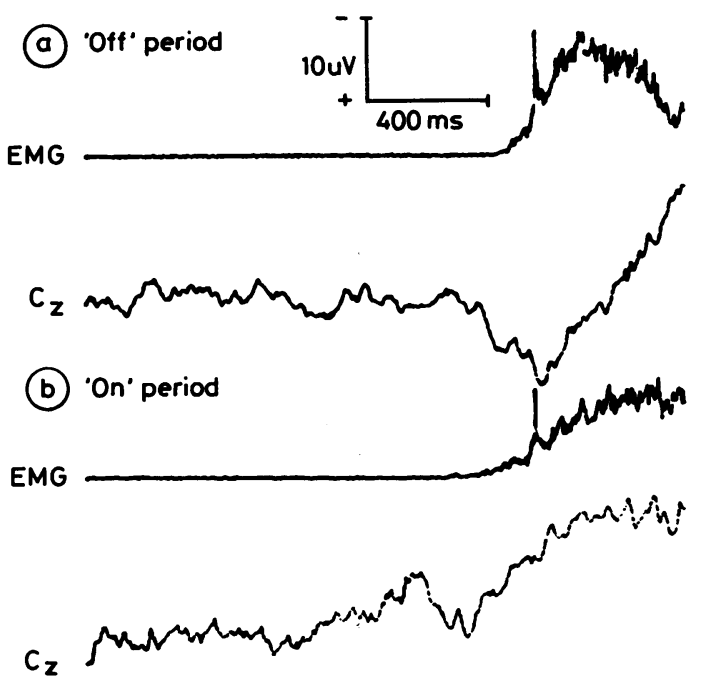

Fig 5 Parkinsonism with "on-off" response to levodopa (female, age $52 \mathrm{yr}$ ). (A) Positive potential replacing $R P$ in "off" period. (B) Negative RP during "on" period of the same day.

with our own have confirmed peak amplitude reduction similar to age matched controls but in both groups, Parkinsonians and normal, the amplitude could be increased by administering levodopa. ${ }^{8}$ There was, however, a slight decrease in the amplitude of the early part of the RP in patients with Parkinson's disease. They confirmed a suggestion that RP amplitude was reduced prior to slowly evolving movements but only with velocities much slower than is usual even in Parkinsonism.

The present work confirms that the RP is decreased in amplitude in subjects with Parkinsonism bilaterally, or ipsilateral to the diseased pallidum in unilateral Parkinsonism, to the extent that the negative wave may be absent or positive as in some normal children and preadolescents ${ }^{14-16}$ and two of our control subjects. Karrer et al ${ }^{16}$ speculated that the positive wave may reflect greater inhibitory effort by the young person to control irrelevant behaviour. We find this difficult to accept though some other aspect of cerebral maturation is possible. It would imply a separate source for the positive going "readiness" potential found in some of our patients with Parkinsonism though it is possible that a posterior spread of the pre-frontal positive wave preceding movement ${ }^{1}$ could (algebraically) cancel a vertex negative potential.

According to the report of Shibasaki et al ${ }^{5}$ we had postulated that a prolonged pre-movement cortical potential might be a marker for the delay of Parkin- son's disease patients in initiating movement. We avoid the term "akinesia" since the term as used by some authors ${ }^{8}$ includes initiation and performance times. On the contrary, from our first case it was clear that the Readiness Potential is shortened rather than lengthened. We have described this as a reduced duration but wish to point out that the time measurement extends backwards from the trigger point derived from muscular activity. This does not exclude the possibility that a negative wave of normal duration is displaced in time, ending as well as starting late, possibly after the premotion positivity and movement potential. This possibility is suggested by recordings directly from areas $6 \mathrm{a}$ alpha and $6 \mathrm{a}$ beta of the human cerebral cortex in which the maximum negativity of the slow deflection occurred "long after the time of the trigger mark as caused by the pressing of the button with the contralateral thumb" (about $260 \mathrm{~ms}$ measured from their fig 2). ${ }^{12}$ A time shift would result in a reduced amplitude at all times up to the trigger point and would be compatible with our findings and those of earlier workers. We do not have suitable recordings of the post-movement epoch to comment further, but inspection of records makes this unlikely and a subsequent report ${ }^{8}$ found normal timing of the peak of RP negativity (N1) relative to EMG onset. For the present purpose it is sufficient to state that we find no evidence for a longer than usual delay between intent to move and the actual contraction of the reference muscle. Indeed the contrary finding encourages us to look for an alternative explanation of the Readiness Potential. If it is a diffuse field effect of thalamocortical neurons, it might cause a threshold shift. The slow rising potential suggests a spatially distributed electro-responsiveness rather than a somatotopic one. We speculate on an analogy with the calcium dependent dendritic potential of Purkinje cells (the climbing fibre response) and wonder if this could be a similar gating signal, perhaps on basket cells. The cerebellar analogue allows the Purkinje cell to have two different reactions according to its input ${ }^{17}$ which would be very suitable for a switch control.

The findings reported here indicate that the RP is modified by dopaminergic therapy pari passu with fluctuations in the clinical response of Parkinsonian patients with respect to self-paced ("voluntary") movement but not with reaction or movement times in response to external stimuli. If the readiness potential is indicative of functional activity of the supplementary motor area, as currently postulated, it would appear that this cortical area is involved in voluntary movement but not obligatory, permissive rather than commanding. We have stressed the time factor since we had expected to find prolonged pre-motion negativity at the vertex in patients with delayed initiation 
of movement but it must be emphasised that our findings are not incompatible with those of previous workers. Our recordings did show reduced peak amplitude of $\mathrm{Nl}$ and decreased amplitude throughout the development of the RP. While this paper was being written, Barrett et al ${ }^{9}$ described three different gradients in the cortical activity preceding EMG onset and now restrict the term Bereitschaftspotential to the first and shallowest of these, followed by intermediate shift and NS ${ }^{1}$ gradients each steeper than the previous and each with differing topographic distributions. It is possible that a general reduction of amplitude could compromise recognition of the low gradient first potential shift. If the first part of the pre-movement cortical potential is, indeed, a gating potential then there would be no functional difference between the timing and amplitude explanations since time to threshold would be the important parameter. In a preliminary communication we have suggested that a striato-thalamo-cortical projection to the supplementary motor area may provide a dopaminergic gate control for postural stabilisation associated with self-paced voluntary movements and that this is defective in Parkinson's disease. ${ }^{6}$ The dopaminedependent neurons may be corticopetal and there are other event-related cortical potentials which are reduced in amplitude in Parkinsonism, including $\mathrm{P} 00^{18}$ and the contingent negative variation. ${ }^{19}$ Nevertheless, the relationship with an "on-off" response to dopaminergic drugs and the other clinical features described above prejudice us in favour of a striato-thalamic "gate".

\section{References}

I Deecke L, 'Scheid P, Kornhuber HH. Distribution of Readiness Potential, Pre-motion Positivity and Motor Potential of the human cerebral cortex preceding voluntary finger movements. Exp Brain Res 1969;7:158-68.

2 Oldfield RC. The assessment and analysis of handedness: The Edinburgh Inventory. Neuropsychologia 1971;9: 97-113.

3 Shagass C, Schwartz M. Visual cerebral evoked response characteristics in, a psychiatric population. Am J Psychiatry 1965;121:979-87.

4 Shibasaki H, Barrett G, Halliday E, Halliday AM. Components of the movement-related cortical potential and their scalp topography. Electroencephalogr Clin Neurophysiol 1980;49:213-26.

5 Shibasaki H, Shina F, Kuroiwa Y. Clinical studies of the movement-related cortical potential (MP) and the relationship between the dentatorubrothalamic pathway and readiness potential (RP). J Neurol 1978;219:15-25.
6 Simpson JA, Khuraibet AJ. Readiness potential of cortical area 6 in Parkinson's disease. Evidence for a dopaminergic striatal control of postural set involving supplementary motor area. J Neurol Neurosurg Psychiatry 1986;49:475.

7 Barrett G, Shibasaki H, Neshige R. A computer-assisted method for averaging movement-related cortical potentials with respect to EMG onset. Electroencephalogr Clin Neurophysiol 1985;60:276-81.

8 Dick JPR, Cantello R, Buruma O, et al. The Bereitschaftspotential, L-Dopa and Parkinson's Disease. Electroencephalogr Clin Neurophysiol (in press).

9 Barrett G, Shibasaki H, Neshige R. Cortical potentials preceding voluntary movement: evidence for three periods of preparation in man. Electroencephalogr Clin Neurophysiol 1986;63:327-39.

10 Barrett G, Shibasaki H, Neshige R. Cortical potential shifts preceding voluntary movement are normal in Parkinsonism. Electroencephalogr Clin Neurophysiol 1986;63:340-8.

11 Deecke L, Englitz HG, Kornhuber HH, Schmitt G. Cerebral potential preceding voluntary movement in patients with bilateral or unilateral Parkinson akinesia. In: Desmedt JE ed. Progress in Clinical Neurophysiology. Basel: Karger, 1977;1:151-63.

12 Groll-Knapp E, Ganglberger JA, Haider M. Voluntary movement-related slow potentials in cortex and thalamus. In: Desmedt JE ed. Progress in Clinical Neurophysiology. Basel: Karger, 1977;1:164-73.

13 Papakostopoulos D, Banerji N. Movement related brain macropotentials during skilled performance in Parkinson's Disease. Electroencephalogr Clin Neurophysiol 1980;49:93P.

14 Timsit-Berthier M, Hausman J. Etude de la VCN et du phenomene de preparation motrice chez des enfants de 5 a 15 ans. Rev Electroencephalogr Neurophysiol Clin 1972;2:141-6.

15 Kurtzberg D, Vaughan HG, Kreuzer J. Task related cortical potentials in children. In: Desmedt JE, ed. Progress in Clinical Neurophysiology. Basel: Karger, 1977;6:216-23.

16 Karrer R, Warren C, Ruth R. Steady potential activity of the brain preceding non-cued and cued movement. In: Otto DA, ed. Multidisciplinary Perspectives in Event-related Brain Potential Research. Washington DC: US Govt Printing Office, 1978:322-9.

17 Martinez FE, Crill WE, Kennedy TT. Electrogenesis of cerebellar Purkinje cell responses in cats. $J$ Neurophysiol 1971;34:348-56.

18 Bodis-Wollner I, Yahr MD, Mylin LH. Nonmotor functions of the basal ganglia. In: Hassler RG, Christ JF, eds. Parkinson-specific Motor and Mental Disorders. Advances in Neurology, 1984;40:289-98.

19 Amabile G, Fattaposta F, Pozzessere G, Albani G, Samarelli L, Rizzo PA, Morocuti C. Parkinson Disease: electrophysiological (CNV) analysis related to pharmacological treatment. Electroencephalogr Clin Neurophysiol 1986;64:521-4. 